\title{
SOROPREVALÊNCIA PARA INFECÇÃO PELO VÍRUS DA HEPATITE C ENTRE INDIVÍDUOS ATENDIDOS NO LABORATÓRIO MUNICIPAL DE SANTA MARIA-RS
}

\author{
Renize Rosa Lubini*, Sandra Trevisan Beck*
}

RESUMO: Para determinar a soroprevalência para infecção pelo vírus da Hepatite $C$, foram analisados os resultados dos testes sorológicos para o marcador anti-HCV em 1416 indivíduos atendidos no Laboratório Municipal de Santa Maria-RS, no período de Julho de 2008 a julho de 2010. A frequencia do marcador anti-HCV foi de 3,9\%. Em relação ao sexo, entre os indivíduos reagentes, $44 \%$ são do sexo feminino e $56 \%$ do sexo masculino. A média de idade nos dois grupos foi semelhante, sendo de 42 anos no sexo feminino (intervalo de 6-68 anos) e 40 anos no sexo masculino (intervalo de 1-71 anos). Pela prevalência sorológica encontrada, a infecção pelo vírus da hepatite $C$ no município é discretamente maior que a relatada por outros estudos em outras regiões do Brasil, com faixa etária sugerindo infecção em um passado recente. Políticas públicas para identificação dos indivíduos infectados precisam ser intensificadas para conter a transmissão deste agente infeccioso.

Descritores: Hepatite C; Anticorpos; Prevalência.

\section{SEROPREVALENCE OF HEPATITIS C INFECTION AMONG INDIVIDUALS ASSISTED AT THE MUNICIPAL LABORATORY IN SANTA MARIA-RS}

ABSTRACT: We analyzed the results of serological tests for anti-HCV antibodies of 1416 individuals attended at the Municipal Laboratory in Santa Maria-RS between July of 2008 to July of 2010 to determine the seroprevalence of Hepatitis $\mathrm{C}$ infection.. The frequency of anti-HCV marker was 3,9\%. Regarding genre , $44 \%$ were female and $56 \%$ male. The mean age for both groups was similar, being 42 years old for females (range 6-68 years old) and 40 years old for males (range 1-71 years old). The seroprevalence of hepatitis C infection in Santa Maria is slightly higher than that reported by other studies in other regions of Brazil, with range of age suggesting infection in the recent past. Public policies for identification of infected individuals must be intensified to stop transmission of this infectious agent.

Descriptors: Hepatitis C; Antibodies; Prevalence.

\footnotetext{
* Acadêmica do Curso de Farmácia da Universidade Federal de Santa Maria, Santa Maria, RS.

** Professora Adjunta do Departamento de Análises Clínicas e toxicológicas, Universidade Federal de Santa Maria, Santa Maria, RS
} 


\section{Introdução}

A Hepatite $\mathrm{C}$ é uma doença infecciosa viral, contagiosa, tendo como causador o vírus da hepatite $\mathrm{C}(\mathrm{HCV})$, o qual provavelmente foi responsável por aproximadamente $90 \%$ dos casos de hepatite transmitida por transfusão de sangue sem agente etiológico reconhecido, anteriormente chamado de Hepatite Não A Não B. Aproximadamente, $80 \%$ das pessoas que se infectam não conseguem eliminar o vírus, evoluindo então para formas crônicas. 0 restante (20\%) consegue eliminá-lo dentro de um período de seis meses do início da infeç̧ão ${ }^{1}$

0 vírus provoca uma infecção persistente, embora alguns indivíduos controlem a infecção de forma espontânea. A coordenação das várias funções efetoras imunológicas é necessária para controlar $\mathrm{O} \mathrm{HCV}^{2}$. $\mathrm{O}$ sucesso das respostas imunológicas parece ser multiespecífico e sustentado, incluindo um papel importante para linfócitos T CD4 ${ }^{+}$. Algumas células TCD8+ mostram reduzida capacidade de secretar citocinas antivirais por período temporário ou em longo prazo. A transmissão do vírus da hepatite $C$ ocorre principalmente por exposição parenteral através de agulhas ou outros objetos perfurantes. A transfusão de sangue e derivados, procedimentos odontológicos, cirúrgicos e de hemodiálise, realizados sem atender às indicações das normas de biossegurança, bem como o uso de drogas injetáveis, podem levar à infecção A transmissão perinatal também pode ocorrer, em $3,6 \%$ a $35,55 \%$ dos casos, sendo que esta infecção dependerá principalmente da quantidade de vírus circulante durante 0 parto e também da co-infecção com o Vírus da Imunodeficiência Humana (HIV). Em risco menor que os citados, a transmissão por saliva, leite materno, sêmen, secreção vaginal, também pode ocorrer ${ }^{3}$.

Há estimativa de que $3 \%$ da população mundial estejam infectadas com o vírus, sendo este 0 principal motivo dos casos de cirrose e, eventualmente, o causador de hepatocarcinoma. Esta proporção deve aumentar segundo a Organização Mundial da Saúde (OMS), a qual afirma que há expectativa de que ocorram 4 milhões de novos casos a cada ano, ${ }^{4,5}$. Além disso, há dados referentes ao ano 2000 que relatam aproximadamente duas vezes mais homens infectados do que mulheres (WHO, 2000) ${ }^{5}$.

Com base em dados da rede de hemocentros, em 2004, a distribuição de casos de HCV variou entre as regiões brasileiras: $2,1 \%$ no Norte; $1 \%$ no Nordeste; $1,2 \%$ no Centro-Oeste; $1,4 \%$ no Sudeste e $0,7 \%$ no Sul ${ }^{6}$.

O diagnóstico laboratorial do vírus HCV pode ser realizado por analises sorológicas, porém, os anticorpos específicos contra o vírus podem demorar até 6 semanas para serem detectados no sangue dos pacientes. A investigação inicial da infecção pelo HCV consiste na realização de exames imunoenzimáticos (ELISA) para detecção de anticorpos específicos contra proteínas virais, sendo o anti-HCV de $3^{a}$ geração (ou ELISA-III) o teste de triagem sorológica, com alta sensibilidade (maior que 97\%) e especificidade próxima de 95\%. Embora esse teste seja muito sensivel para rastreamento de soropositivos para HCV e tenha quase que eliminado a ocorrência de hepatite pós-transfusional, seu resultado pode mostrar-se falsonegativo. Isto ocorre devido à soroconversão (presença de anticorpos detectáveis) ocorrer aproximadamente 12 semanas após a exposição inicial ao vírus. Então, no período de "janela imunológica" (doença presente, com anticorpos ausentes), os testes que pesquisam apenas

Saúde (Santa Maria), v.36, n.2, p. 71-78,

jul./dez. 2010.

Soroprevalência para infecção pelo virus da hepatite c entre indivíduos atendidos no Laboratório Municipal de Santa Maria- RS anticorpos, resultarão negativos ${ }^{7}$.

Atualmente existem disponiveis comercialmente os ensaios de $4^{\mathrm{a}}$ geração. Esses são testes imunoenzimáticos que detectam não só anticorpos, mas também antígenos virais circulantes, os quais aparecem precocemente na fase aguda da doença, diminuindo a chamada janela sorológica e também reduzindo o número de resultados indeterminados 8 . 
As reações falso-positivas também podem ocorrer, embora com pouca frequencia, devido à excelente especificidade dos reagentes disponíveis no mercado. A confirmação de um ELISA positivo pode ser realizada por testes suplementares como o Immunoblot recombinante (RIBA), mais específicos e geralmente empregados para verificar falso-positivos em indivíduos com baixo risco de infecção $0^{9}$. A reação em cadeia da polimerase (PCR) é uma das técnicas de biologia molecular mais utilizada, que amplifica parte do genoma do vírus, sendo extremamente sensível ${ }^{10}$. Este teste, uma vez que detecta o genoma viral, permite confirmar a infecção pelo HCV. O teste de PCR pode ser qualitativo para detecção do vírus ou quantitativo para quantificação do número de cópias virais circulantes ou carga viral11.

Uma vez que os indivíduos atendidos no Laboratório Municipal de Santa Maria- RS provêm de diferentes áreas do município, e podem representar uma amostragem da população geral, o presente trabalho teve por objetivo determinar a soroprevalência da infecção pelo vírus da Hepatite $\mathrm{C}$ entre os indivíduos que realizaram sorologia para detecção de anticorpos anti$\mathrm{HCV}$.

\section{Material e métodos}

Foram analisados os resultados de 1416 sorologias para HCV no período de Julho de 2008 a julho de 2010 realizadas no Laboratório de Análises Clínicas da Prefeitura de Santa Maria - (CEDAS). O levantamento dos dados foi obtido a partir de registros arquivados no referido laboratório.

Os testes sorológicos foram realizados utilizando equipamento automatizado AXSYM (Abbott ${ }^{\circledR}$ ), e reagentes comerciais aprovados pela ANVISA, pelo método de Ensaio Imunoenzimático por Micropartículas (MEIA) para detecção qualitativa do anticorpo para 0 vírus da Hepatite $\mathrm{C}$ em soro ou plasma humano.

Para verificar a intensidade da resposta humoral dos indivíduos testados, os resultados sorológicos obtidos foram expressos em forma de index, onde a densidade ótica do resultado obtido com a amostra testada foi dividida pela densidade ótica definida como ponto de corte da reação (cut off). Valores maiores que 1.0 foram considerados reagentes.

\section{Considerações éticas}

Os dados foram obtidos após avaliação e autorização para realização do projeto pela Secretaria de Município de Saúde de Santa Maria e Comitê de Ética da UFSM sob CAAE (Certificado de Apresentação para Apreciação Ética): 0174. 0.243.000-10.

\section{Resultados}

$\mathrm{Na}$ análise inicial ( $\mathrm{n}=1416)$, verificou-se que 1359 (96\%) resultaram não reagentes para sorologia anti-HCV. Para estes pacientes, o resultado foi liberado, sem necessidade da análise de uma segunda amostra. Para os 57 pacientes, com resultado reagente (4\%), foi solicitado

coleta de uma nova amostra para repetição do teste sorológico. Apenas um paciente não

Saúde (Santa Maria), v.36, n.2, p. 71-78, jul./dez. 2010

Lubini, R. R.; Beck, S. T.

ISSN 2236-5843 
compareceu para a segunda coleta, e outro teve o resultado da segunda amostra não reagente. $O$ resultado sorológico foi então confirmado como reagente em 55 dos casos (3,9\%). (Figura 1)

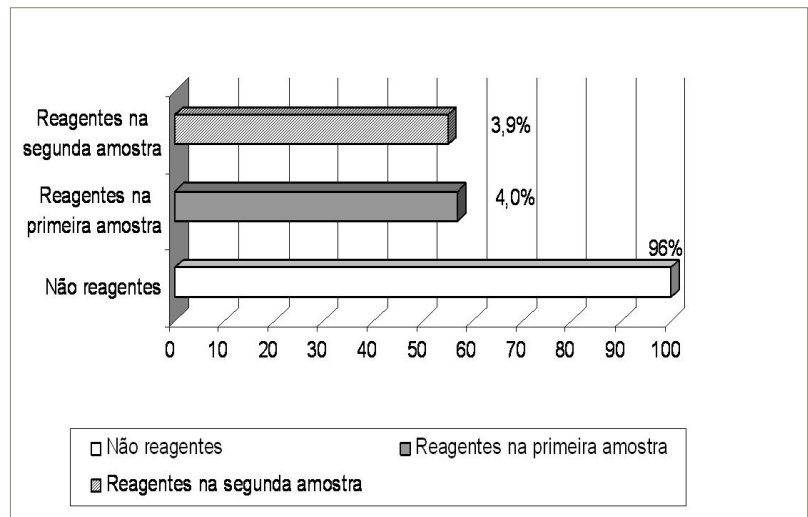

Figura 1 - Resultados sorológicos encontrados para anticorpos anti-HCV nas amostras estudadas

Em relação ao sexo, entre os indivíduos reagentes, $44 \%$ eram do sexo feminino e $56 \%$ do sexo masculino. A média de idade nos dois grupos foi semelhante, sendo de 42 anos no sexo feminino (intervalo de 6-68 anos) e 40 anos no sexo masculino (intervalo de 1-71 anos).

Considerando a intensidade da resposta sorológica da primeira amostra testada, pode-se verificar que a maior parte dos pacientes apresentava resposta sorológica com índex maior que $2.0(82 \%)$. Apenas 10 pacientes apresentaram índex entre 1,0 e 2,0, sendo três deles com valor muito próximo ao ponto de corte da reação (entre 1-1,5) e, portanto, podendo ser considerado fracamente reagente (Figura 2).

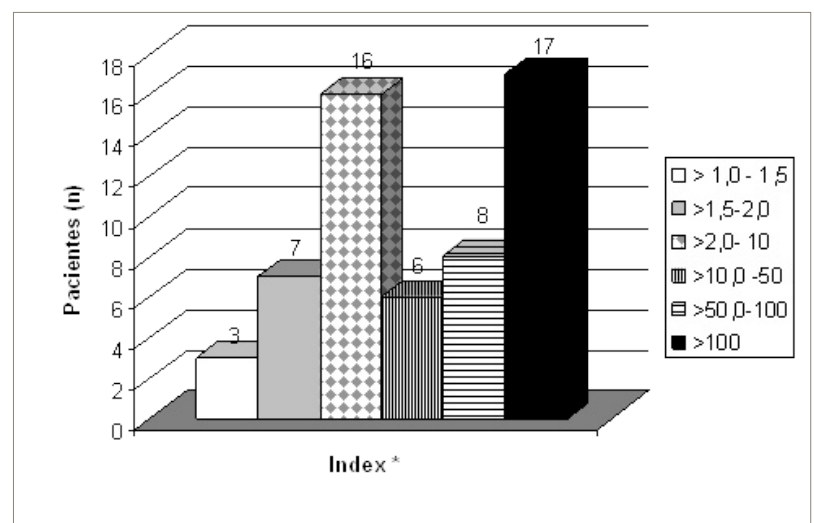

Figura 2 - Índex sorológicos encontrados entre os indivíduos reagentes para anticorpos anti-HCV. *Índex = valor de leitura da amostra / valor do ponto de corte da reação Teste reagente $=$ index $>1,0$

\section{Discussão}

Saúde (Santa Maria), v.36, n.2, p. 71-78, jul./dez. 2010. Soroprevalência para infecção pelo virus da hepatite c entre indivíduos atendidos no Laboratório Municipal de Santa Maria- RS 74 ISSN 2236-5834

Um dos maiores problemas da infecção pelo vírus da Hepatite $\mathrm{C}$ (HCV) é ser frequentemente assintomática. Apesar de silenciosa, esta infecção é uma das principais causas de cirrose e hepatocarcinomas e a principal indicação de transplante hepático ${ }^{12}$. Em uma pesquisa realizada pela Sociedade Brasileira de Hepatologia para analisar a "Epidemiologia do vírus C no Brasil" foi observada a prevalência de anti-HCV em pacientes com diferentes doenças hematológicas $(2,7$ a $51 \%)$, pré-doadores de sangue $(1,23 \%)$ e hemodialisados $(38,35 \%)$, entre outros. Foi observada também uma importante diferença na taxa de positividade em politransfundidos, antes $(18, \%)$ e depois de $1991(1,38 \%)^{13}$. 
A prevalência do vírus no Brasil varia principalmente de acordo com as características demográficas e sócio-econômicas da população estudada, sendo a região norte a de maior endemicidade ${ }^{14}$. Quando voltados para segmentos específicos da população, os resultados demonstram ampla variação desta medida, incluindo valores como $1,1 \%$ a 2,4\% para a população geral na região amazônica ${ }^{15}, 15 \%$ entre alcoólatras estudados em Porto Alegre 16, chegando a $56 \%$ entre hemofílicos com idade superior a 10 anos na Bahia ${ }^{17}$. Já em grupos de risco, observa-se alta prevalência ( $48,1 \%$ a $51,9 \%$ ), entre hemodialisados ${ }^{18}$.

A prevalência de $4 \%$ de indivíduos com resultado reagente na primeira amostra, encontrada no presente estudo (figura 1), foi pouco superior que à descrita em estudo realizado no estado do Pará, onde a prevalência do anticorpo anti-HCV foi de 3,6\% ${ }^{19}$. Esta porcentagem também foi superior à estimativa mundial, que até 2007 era de 2,2\% ${ }^{20}$. Comparando com os dados apresentados pelo Ministério da Saúde em 200421, onde a infecção já havia atingido $2 \%$ da população brasileira, percebe-se que a porcentagem de indivíduos infectados pelo vírus vem aumentando de forma gradual.

Apesar de não ter sido realizado o teste confirmatório RIBA, para as amostras com resultados reagentes para anticorpos anti-HCV, pode-se estimar que 0 índice de resultados falso-positivos foi muito baixo. Esta conclusão baseia-se em estudo realizado por Contreras e colaboradores em 200822, para confirmar pesquisa de anticorpos anti-HCV sem necessidade de um teste complementar. Os autores demonstraram que, utilizando o ensaio da Ortho VITROS anti-HCV de terceira geração, em amostras de doadores de sangue, um índex igual a 4,0 confirmaria um resultado verdadeiramente positivo, relatando que pacientes com índex inferior a 2,0 raramente apresentavam viremia. Como no presente estudo, a maior parte dos pacientes apresentou um índex sorológico elevado, embora realizado com reagente diferente do estudo citado, a probabilidade dos resultados de ELISA ser verdadeiros é alta. Porém, realização do teste da PCR continua sendo importante, não só para a confirmação da infecção, principalmente nos pacientes apresentando índex entre 2,0 e 4,0, como para acompanhamento da eficácia do tratamento, quando este é instituído.

Quando os resultados reagentes foram analisados segundo o sexo, a maior prevalência do marcador pesquisado foi encontrada em homens (56\% dos casos), indicando que estes podem ter tido maior exposição ao vírus HCV. Porém, não há evidências que comprovem uma maior suscetibilidade desse sexo à infecção viral. A prevalência maior no sexo masculino se deve, provavelmente, devido ao comportamento sexual. Um estudo realizado no Hemocentro de Ribeirão Preto- SP também evidenciou o predomínio de homens (93\%) para os resultados reagentes quanto à sorologia para HCV. Contudo isto pode ser simplesmente um viés amostral, uma vez que a maior parte dos doadores de sangue é do sexo masculino ${ }^{23}$. Em pesquisa realizada para traçar um panorama da infecção por hepatite $C$ no estado de Santa Catarina e em Florianópolis, no sexo masculino foi encontrada uma prevalência de $69,59 \%$ e $69,54 \%$ respectivamente ${ }^{24}$. O mesmo pôde-se observar em outros achados, como nas populações de São Paulo $(69,3 \%)$ e Belém $(74,1 \%)^{25}$.

Em relação à faixa etária, no grupo estudado a média de idade em ambos os sexos foi de 40 a 42 anos. Uma análise idade-específica de dados de prevalência identificou três padrões gerais de transmissão do HCV, na primeira delas a maioria das infecções são encontradas em indivíduos com idade entre 30-49 anos, o que indica que o risco de transmissão foi maior em um passado relativamente recente (10-30 anos), e principalmente afetando adultos jovens, semelhante ao encontrado no presente estudo. Outros estudos realizados no Brasil confirmam esta tendência, como o realizado no laboratório público do Pará, onde a faixa etária com maior

Saúde (Santa Maria), v.36, n.2, p. 71-78, jul./dez. 2010 Lubini, R. R.; Beck, S. T. ISSN 2236-5843 
prevalência foi entre 30 e 50 anos de idade ${ }^{19}$. Um estudo feito entre doadores de sangue, também indica maior prevalência de soropositivos para hepatite $C$ entre indivíduos com 26-54 anos de idade23. Contudo este grupo não é um indicador fiel da soroprevalência geral, pois existe uma idade mínima (18 anos) para que o indivíduo possa ser doador, sendo assim uma amostra selecionada. 0 segundo padrão de transmissão está presente em países como 0 Japão e Itália, onde a maioria das infecções é encontrada em pacientes idosos, o que mostra que o risco de transmissão foi em um passado distante. Já em países com o terceiro padrão, como o Egito, as altas taxas de infecção são observadas em todas as faixas etárias, indicando um elevado risco em curso para a aquisição da infecção pelo HCV. Nos dois últimos grupos a contaminação de equipamentos para administrar injeções e procedimentos inseguros de saúde são meios importantes de transmissão ${ }^{26}$.

Devido à similaridade em suas rotas de transmissão (via parenteral), a co-infecção do HCV em pessoas portadoras do vírus da imunodeficiência humana (HIV) é freqüentemente observada, principalmente em pacientes que adquiriram HIV por uso de drogas injetáveis ou transfusão sanguínea. Nos Estados Unidos e Europa, estima-se que 30\% dos indivíduos com HIV estejam co-infectados com HCV, no Brasil, a prevalência depende da área geográfica considerada, variando de $8,9 \%$ a $54 \%{ }^{27}$.

Estes dados corroboram a importância do conhecimento da infecção por HCV na população geral, e a necessidade destes indivíduos serem também pesquisados em relação à infecção pelo HIV. Uma vez identificado o indivíduo infectado pode ser evitada a transmissão do agente infeccioso, colaborando para o controle da doença na população geral.

\section{Referências Bibliográficas}

1. BRASIL. Ministério da Saúde. Programa Nacional para a Prevenção e o Controle das Hepatites Virais. Manual de Aconselhamento em Hepatites Virais, 2005. Disponível em: http://bvsms.saude.gov.br/bvs/politicas/hepatites_aconselhamento.pdf. Acesso em 26 de maio de 2010.

2. KLENERMAN, P.; LUCAS, M.; BARNES, E.; HARCOURT, G. Immunity to hepatitis $C$ virus: stunned but not defeated. Microbes Infect. , 2002; 4: (1): 57-65.

3. STRAUSS, E. Hepatite C. Rev Soc Bras Med Trop, 2001; 34(1): 69-82.

4. CIMERMAN, S. Hepatite C: A epidemia silenciosa. 2005. Disponível em: http://www.lincx.com.br/lincx/saude_a_z/outras_doencas/hepatite.asp. Acesso em 25 de maio de 2010.

5. WORLD HEALTH ORGANIZATION (WHO). Hepatitis C. Disponivel em: http://www.who.int/csr/disease/hepatitis/whocdscsrlyo2003/en/index4.html\#endemicity. Acesso em 06 de junho de 2010.

6. ROSINI, N.; MOUSSE, D.; SPADA, C.; TREITINGER, A. Seroprevalence of HbsAg, Anti- HBc and Anti-HCV in Southern Brazil, 1999-2001. Braz J Infect Dis, 2003; 7(4): 262-267.

7. NATIONAL INSTITUTES OF HEALTH. Consensus Development Conference Statement: Manegement of Hepatitis C: Hepatology, , 2002; 19: 3-20.

Saúde (Santa Maria), v.36, n.2, p. 71-78,

hepatite c entre indivíduos atendidos no

Laboratório Municipal de Santa Maria- RS

76
ISSN 2236-5834
8. SHAH, D. O.; CHANG, C. D.; JIANG, L. X.; CHENG, K.Y.; MUERHOFF, A. S.; GUTIERREZ, R.A.; LEARY, T.P.; et al. Combination HCV core antigen and antibody assay on a fully automated chemiluminescence analyzer. Transfusion; 2003; 43:1067-1074.

9. KIM YS, LEE HS, AHN YO. Factors associated with positive predictability of the anti-HCV ELISA method with confirmatory RT-PCR. J Korean; Med Sci. 1999;14(6):629-34. 
10. NOLTE, F.S.; FRIED, M.W.; SHIFFMAN, M.L.; FERREIRA-GONZALEZ, A.; GARRETT, C.T.; SCHIFF, et al. Prospective Multicenter Clinical Evaluation of Amplicor and Cobas Amplicor Hepatitis C Virus Tests. J Clin Microbiol, 2001; 39: 4005- 4012.

11. GERMER, J. J. \& ZEIN, N. N. Advances in the molecular diagnosis of hepatitis $C$ and their clinical implications. Mayo Clinc Proc, 2001;76: 911-920.

12. VELOSA, J.; MARINHO, R.; GOUVEIA, A. Factores de risco para o carcinoma hepatocelular em doentes com cirrose hepática. J Port Gastroenterol, 1994; 1: 1-10.

13. SBH -Relatório do Grupo de Estudos da Sociedade Brasileira de Hepatologia. Epidemiologia da infecção pelo vírus da Hepatite C no Brasil. Disponível em: http://www.fmt.am.gov.br/trabalhos/anais/virologia/infec_brasil.htm. Acesso em 12 de novembro de 2010.

14. FERREIRA, C.T.; SILVEIRA, T.R. Hepatites virais: aspectos da epidemiologia e da prevenção. Rev Bras Epidemiol., 2004;7: 473-487.

15. TAVARES-NETO, J.; ALMEIDA, D.; SOARES, M.C.; UCHOA, R.; VIANA, S.; DARUB, R. et al. Seroprevalence of hepatitis $B$ and $C$ in the western Brazilian Amazon region (Rio Branco, Acre): a pilot study carried out during a hepatitis B vaccination program. Braz J Infect Dis. 2004; 8: 133-139.

16. GALPERIM, B.; CHEINQUER, H.; STEIN, A.; FONSECA, A.; LUNGE, V.; IKUTA, N. Prevalence of hepatitis $C$ virus in alcoholic patients: role of parenteral risk factors. Arq Gastroenterol, 2006; 43 (2): 81-84.

17. SILVA, L.K.; SILVA, M.B.S.; LOPES, G.B.; RODART, I.F.; COSTA, F.Q.; SANTANA, N.P. et al. Prevalence of hepatitis $C$ virus infection and HCV genotypes among hemophiliacs in the State of Bahia, Northeastern Brazil: analysis of serological and virological parameters. Rev Soc Bras Med Trop, 2005; 38(6): 496-502.

18. FABRIZI F, MARTIN P. Health care associated transmission of hepatitis $B$ and $C$ viruses in hemodialysis units. Clin Liver Dis, 2010; 14: 49-60.

19. AQUINO, J.A.; PEGADO, K.; BARROS, L.; MACHADO, L. Soroprevalência de infecções por vírus da hepatite B e vírus da hepatite C em indivíduos do Estado do Pará. Rev Soc Bras Med Trop, 2008; 41(4): 334337.

20. ALTER MJ. Epidemiology of viral hepatitis C infection. World J Gastroenterol, 2007;13(17):2436-41

21. BRASIL, Ministério da Saúde. Programa Estadual de DST/AIDS divisão de Vigilância Epidemiológica. Boletim Epidemiológico DST/AIDS. Ano II, n. 01, 2004. Disponível em: http://bvsms.saude.gov.br/bvs/periodicos/03boletim_588906.pdf. Acesso em 25 de maio de 2010.

22. CONTRERAS, A. M.; TORNERO-ROMO, C.M.; TORIBIO, J.G.; CELIS, A.; OROZCO-HERNÁNDEZ, A.; RIVERA, P.K.; MENDEZ, C.; et al. Very Low Hepatitis C Antibody Levels Avoid Supplemental Testing. Transfusion, 2008; 48: 2540-2548.

23. VALENTE, V.B.; COVAS, D.T.; PASSOS, A.D.C. Marcadores sorológicos das hepatites B e C em doadores de sangue do Hemocentro de Ribeirão Preto, SP. Rev Soc Bras Med Trop, 2005; 38: 488-492.

24. GONÇALVES, S.; DAMINELLI, E.N.; SPADA, C.; HAAS, P. Panorama da Hepatite C no estado de Santa Catarina e na cidade de Florianópolis. RBCA, 2008; 40(1): 57-60

25. MONTEIRO, M.R.C.C. Estudo soro epidemiológico dos vírus da hepatite $B$ e hepatite $\mathrm{C}$ em portadores do Vírus da Imunodeficiência Humana/Sida na cidade de Belém, Pará - Brasil. Tese de Doutoramento, Faculdade de Medicina de Ribeirão Preto da Universidade de São Paulo, Ribeirão Preto, SP, 2002.

26. WASLEY, A.; ALTER, M. J. Epidemiology of hepatitis C: geographic differences and temporal trends. Semin Liver Dis, 2000; 20: 1-16.

27. CARVALHO, F. H. P.; COELHO, M.R.C.D.; VILELLA, T.A.S.; SILVA, J.L.A.; MELO, H.R.L. Co-infecção HIV/HCV em hospital universitário de Recife, Brasil. Rev Saúde Pública, 2009; 43(1): 133-39. 
Recebido em 15 de fevereiro de 2011.

Aprovado em 10 de junho de 2011.

Saúde (Santa Maria), v.36, n.2, p. 71-78,

jul./dez. 2010.

Soroprevalência para infecção pelo vírus da

hepatite $c$ entre indivíduos atendidos no

Laboratório Municipal de Santa Maria- RS

78 |

ISSN 2236-5834 